\title{
A Educação em Direitos Humanos nos Projetos Político-Pedagógicos das escolas de São Paulo
}

\section{Human Rights Education in Political-Pedagogical Projects of São Paulo's schools}

\author{
Ana Maria Klein ${ }^{1}$ \\ Solange Lima D’Água ${ }^{1}$
}

\begin{abstract}
RESUMO
$\mathrm{O}$ artigo traz os dados de uma pesquisa qualitativa que teve por objetivo levantar, por meio da análise dos Projetos Político-Pedagógicos (PPPs), a presença de elementos que integram conhecimentos, valores e práticas da Educação em Direitos Humanos (EDH) nas escolas públicas do estado de São Paulo. Foram analisados 15 documentos a partir de critérios estabelecidos com base em documentos-referência para a EDH no país. Os critérios foram organizados em sete âmbitos: comunidade interna e externa; princípios e concepções de educação; objetivos; currículo; participação democrática e ambiente escolar; formação docente e avaliação. Buscou-se identificar se elementos relacionados à EDH estavam ausentes, se eram apenas mencionados ou se destacavam de maneira propositiva, por meio de ações planejadas nos PPPs. Os dados demonstram que os conteúdos diretamente relacionados à EDH estão ausentes dos PPPs, algumas temáticas relacionadas a este tipo de educação são fracamente mencionadas e há ações planejadas pelas escolas que promovem direitos, no entanto, o planejamento intencional, sistematizado e consciente da EDH ainda não se reflete neste tipo de documento.

Palavras-chave: Educação em Direitos Humanos; Projeto Político-Pedagógico; escolas.
\end{abstract}

DOI: $10.1590 / 0104-4060.38443$

1 Universidade Estadual Paulista. Campus São José do Rio Preto. São José do Rio Preto, São Paulo, Brasil. Rua Cristóvão Colombo, 2265 - Jardim Nazareth. CEP: 15054-000. 


\begin{abstract}
The article presents data from a qualitative study that aimed to investigate the presence of aspects that integrate knowledge, values and practice of the Human Rights Education (HRE) in the political-pedagogical projects (PPPs) of public schools in the state of São Paulo. 15 documents were analyzed from criteria based on reference documents for HRE in Brazil. The criteria were organized into seven areas: internal and external community; principles and concepts of education; goals; curriculum; democratic participation and school environment; teacher training and evaluation. We sought to identify whether the HRE related elements were missing, or if they were just mentioned or stood out through propositional planned actions in PPPs. The data demonstrate that the contents directly related to HRE are absent from PPPs, some issues related to this type of education are weakly mentioned and there are some planned actions that promote rights. However, the intentional, systematic and conscious planning of HRE is not yet reflected in this document type.
\end{abstract}

Keywords: Human Rights Education; political-pedagogical project; schools.

\title{
Introdução
}

A Educação em Direitos Humanos (EDH) é um compromisso internacional que ganha corpo no século XX com a Declaração Universal dos Direitos Humanos (ONU, 1945) que afirma em seu preâmbulo a imprescindibilidade da educação para a efetivação destes direitos. Tal premissa foi reiterada em Viena, no ano de 1993, durante a Conferência Mundial das Nações Unidas sobre Direitos Humanos, quando os Estados assumiram internacionalmente a responsabilidade em relação à promoção da $\mathrm{EDH}$, cabendo a cada país o desenvolvimento de ações nesta direção.

No Brasil, o compromisso estatal com a EDH tem como marco o Plano Nacional de Educação em Direitos Humanos - PNEDH (BRASIL, 2006). Em 2010, este compromisso é ratificado e especificado por meio do Programa Nacional de Direitos Humanos 3, PNDH-3 (BRASIL, 2010) que dedica um eixo à educação.

Em 2012 o país deu um passo decisivo em direção à concretização da EDH na educação formal. Em maio do ano em questão, o Conselho Nacional de Educação - CNE, por meio da homologação ministerial, aprovou as Diretrizes Nacionais de Educação em Direitos Humanos (BRASIL, 2012), normas obrigatórias que orientam o planejamento curricular das escolas, instituições 
de Educação Superior e sistemas de ensino. Cabe acrescentar que as referidas Diretrizes foram instituídas pelo Conselho Pleno do CNE, com isso, sua abrangência inclui a Educação Infantil e se estende até a Pós-Graduação.

Diretrizes fixadas pelo CNE têm como intuito orientar as práticas educacionais brasileiras, respeitando as matizes curriculares estaduais e municipais e considerando a autonomia da escola e da sua proposta pedagógica. Com isso, cabe a cada instituição adequar os princípios, fundamentos e procedimentos à sua realidade.

Partindo da autonomia das instituições, o objetivo da presente investigação é levantar, por meio dos Projetos Político-Pedagógicos (PPPs), a presença da EDH nas escolas públicas do estado de São Paulo, uma vez que estes documentos, formulados pelas comunidades escolares, traçam metas e delineiam ações para alcançá-las.

\section{Educação em Direitos Humanos e Projeto Político-Pedagógico}

A EDH entende como direito de todo ser humano o desenvolvimento integral de suas potencialidades, objetivo que é atingido pela educação. Compreende-se por todos a amplitude e a complexidade que caracterizam a espécie humana, portanto, a consideração, o respeito e a valorização da diversidade de modos de ser, pensar, viver, existir devem ser os pressupostos éticos centrais das práticas educativas.

Por conceber a humanidade em sua diversidade, algumas temáticas são imprescindíveis à compreensão e efetivação dos Direitos Humanos, como, por exemplo, diversidade sexual, enfrentamento aos preconceitos, valorização de outras culturas, meio ambiente (como um direito das gerações atuais e futuras), inclusão social, dentre outras que destacam a importância do respeito à amplitude e complexidade que envolve a espécie humana.

Nesse sentido, a EDH configura-se como uma necessidade das sociedades contemporâneas ao orientar suas práticas e relações cotidianas por valores que reconhecem a dignidade e a diversidade humana. Adotar a EDH como eixo vertebral das práticas escolares significa priorizar a formação integral dos estudantes por meio de três dimensões: epistemológica (acesso ao conhecimento e informações relativas aos direitos humanos); axiológica (vivenciar valores relacionados aos Direitos Humanos) e práxis (agir de acordo com os valores e os conhecimentos apreendidos). 
A compreensão e significação dos Direitos Humanos (DH), como diretrizes que orientam os indivíduos na sociedade, implicam na vivência e convivência em ambientes que guiam suas práticas por meio de tais direitos. Por isso, não se trata de um objetivo a ser alcançado e sim de um caminho a ser trilhado, de um modo de vida.

A construção de um ambiente escolar que proporciona simultaneamente conhecimento, respeito, valoração positiva e promoção dos $\mathrm{DH}$ se dá mediante a formulação de um projeto pensado, discutido e orientado para tais fins. Neste sentido, os PPPs são elementos centrais à consolidação da EDH nas escolas, na medida em que são projetos coletivos que expressam simultaneamente o que a escola é e aquilo que ela pretende ser.

O Projeto Político-Pedagógico é político porque forma para a cidadania tendo por referência princípios, valores e práticas democráticas. Além disso, todo projeto desta natureza implica em escolhas sobre o que será ensinado, como será, em quais contextos e como se fará a avaliação. Entendendo o currículo como tudo aquilo que ocupa o tempo escolar (SACRISTAN; GOMÉZ, 2000, p. 184) podemos afirmar que as opções sobre aquilo que fará parte do currículo e aquilo que ficará de fora são decisões políticas, na medida em que expressam uma concepção de sociedade, educação, participação social e a escolha de conteúdos que materializarão estas concepções.

A formulação de um PPP envolve uma reflexão coletiva e o questionamento crucial sobre os conteúdos escolhidos para integrar o currículo. Envolve, também, a consciência e coerência em relação às opções que faz e às metas pretendidas. As metas que guiam os projetos não são definidas aleatoriamente pelos indivíduos, o que significa que não é qualquer meta que vale a pena ser perseguida, senão aquelas que têm importância para a comunidade escolar; a definição de metas, portanto, se efetiva sempre face a um cenário de valores e esses são sócio-históricos e culturalmente situados. Dito de outra forma, o currículo é um reflexo dos valores e anseios da sociedade em uma determinada época e contexto.

Para Veiga (2001), a concepção de um projeto pedagógico deve apresentar características como:

a) ser processo participativo de decisões;

b) preocupar-se em instaurar uma forma de organização de trabalho pedagógico que desvele os conflitos e as contradições;

c) explicitar princípios baseados na autonomia da escola, na solidariedade entre os agentes educativos e no estímulo à participação de todos no projeto comum e coletivo; 
d) conter opções explícitas na direção de superar problemas no decorrer do trabalho educativo voltado para uma realidade específica;

e) explicitar o compromisso com a formação do cidadão. (VEIGA, 2001, p. 11).

A autonomia institucional, a gestão democrática e o engajamento de todos os segmentos da comunidade escolar são condições básicas para que o PPP não seja apenas uma carta de boas intenções.

[...] o projeto é um meio de engajamento coletivo para integrar ações dispersas, criar sinergias no sentido de buscar soluções alternativas para diferentes momentos do trabalho pedagógico-administrativo, desenvolver o sentimento de pertença, mobilizar os protagonistas para a explicitação de objetivos comuns definindo o norte das ações a serem desencadeadas, fortalecer a construção de uma coerência comum, mas indispensável, para que a ação coletiva produza seus efeitos. (VEIGA, 2003, p. 268).

Gadotti (1994, não paginado) destaca que o PPP precisa ser percebido e vivenciado por todos e isso envolve a escolha do livro didático, o planejamento do ensino, o estabelecimento do calendário escolar, a participação efetiva na organização de eventos culturais, de atividades cívicas, esportivas e recreativas. Trata-se de viabilizar a convivência em um ambiente de fato democrático concretizado por meio das relações interpessoais, da organização do trabalho pedagógico (em sala de aula e de todas as atividades fora da sala de aula), das metodologias adotadas, enfim, a participação esperada vai muito além da presença em reuniões, ela se traduz cotidianamente em atitudes, métodos e processos.

Pode-se, portanto, afirmar que um Projeto Político-Pedagógico compreende os conteúdos curriculares, as metodologias e o próprio modo de organizar a vida escolar. Assim sendo, não nega o instituído na escola, mas o confronta com a realidade e as novas exigências sociais, adotando novos horizontes. (GADOTTI, 1994, não paginado).

É precisamente na escolha consciente sobre o que ensinar, como ensinar, com quais objetivos ensinar e sobre quais valores orientam essas escolhas que se insere a reflexão sobre a Educação em Direitos Humanos. Este tipo de educação extrapola a dimensão dos conteúdos e se refere, sobretudo, a um modo de orientar a vida na escola e na sociedade. Envolve valores democráticos e humanos, relações de respeito e solidariedade e conteúdos que visam à formação de sujeitos de direitos. 


\section{Problema e objetivos}

A investigação partiu da problematização sobre quais elementos relacionados à EDH poderiam estar presentes nos Projetos Político-Pedagógicos de escolas paulistas. Objetivou-se mais especificamente averiguar dentre os princípios e concepções de educação destacados no PPP se há elementos concernentes à EDH e às temáticas a ela relativas; detectar se dentre os objetivos destacados no PPP há menção a práticas que promovam a EDH na escola; identificar propostas relacionadas à participação democrática da comunidade escolar em processos decisórios, festividades e discussão de problemas coletivos; e, averiguar a existência de ações voltadas à formação docente em EDH.

\section{Materiais, métodos e procedimentos}

Para elencar os objetivos do estudo e os critérios de análise dos PPPs, utilizou-se como referência ações recomendadas pelos principais documentos que norteiam este tipo de educação no país: Programa Mundial de Educação em Direitos Humanos (ONU, UNESCO, OHCHR, 2006); Plano Nacional de Educação em Direitos Humanos (BRASIL, 2006); Programa Nacional de Direitos Humanos (BRASIL, 2010); Diretrizes Nacionais de Educação em Direitos Humanos (BRASIL, 2012); e o Estatuto da Criança e do Adolescente (BRASIL, 1990), por tratar especificamente de direitos concernentes ao segmento populacional que integra as escolas estudadas.

Para que os critérios estabelecidos não tivessem apenas um caráter documental e refletissem também as práticas escolares foi realizada uma consulta a 41 Secretarias Municipais de Educação de diferentes cidades e estados brasileiros com o intuito de elencar aspectos necessários e possíveis ao desenvolvimento da EDH nas escolas².

Foram propostos sete âmbitos de análise que levam em conta simultaneamente elementos centrais de um PPP e que se relacionam ao desenvolvimento

2 A proposição destes critérios fez parte de um produto técnico desenvolvido para o Ministério da Educação (MEC) e para a Organização das Nações Unidas para a Educação, a Ciência e a Cultura (UNESCO - acrônimo de United Nations Educational, Scientific and Cultural Organization) - Projeto DAS/MEC 00062474(DEX). Contrato BRA10-11203. Consultora: Ana Maria Klein, Brasília: 2010. 
da $\mathrm{EDH}$, a saber: comunidade interna e externa; princípios e concepções de educação; objetivos; currículo; participação democrática e ambiente escolar; formação docente e avaliação. Cada um dos âmbitos apresenta um número variável de critérios e visa identificar se elementos relacionados à EDH estão ausentes, se são apenas mencionados ou se destacam de maneira propositiva, por meio de ações planejadas.

Os PPPs analisados foram obtidos aleatoriamente a partir do contato com as escolas estaduais de ensino fundamental e médio de São Paulo.

Inicialmente foi contatada a Secretaria Estadual de Educação de São Paulo (SEE/SP) que apoiou a pesquisa. A própria secretaria apresentou a proposta às 91 diretorias regionais de ensino do estado e solicitou a sua contribuição na divulgação do projeto. Posteriormente as próprias pesquisadoras entraram em contato com as diretorias regionais via e-mail reforçando a solicitação de que as escolas enviassem seu PPP para um endereço especialmente criado para este fim. Obteve-se o retorno de 15 escolas.

\section{Análise dos Projetos Político-Pedagógicos}

A análise dos PPPs permite a aproximação entre teorias, documentos-referência e a realidade e prática das escolas. Com isso, foi possível identificar os elementos presentes nos PPPs como também detectar quais os âmbitos pesquisados estão mais próximos ou mais distantes de uma educação orientada por princípios da Educação em Direitos Humanos.

\section{Escola e comunidade interna e externa}

A EDH tem como um de seus pressupostos a problematização da realidade a partir dos Direitos Humanos, para tanto conhecer a realidade local da instituição é um passo importante na implementação de projetos voltados a este tipo de educação. Por outro lado, conhecer a realidade interna também é imprescindível, uma vez que o direito à aprendizagem deve ser promovido entre todos/as os/as estudantes. Assim, o primeiro âmbito refere-se à escola e à sua relação com a comunidade interna e externa e apresenta dez critérios para esta caracterização. 


\section{TABELA 1 - ESCOLA E COMUNIDADE INTERNA E EXTERNA}

\begin{tabular}{l|l|l|l}
\hline $\mathrm{n}=15$ & Não menciona & Menciona & Propõe ações \\
\hline 1.1 Problemas da comunidade local & $40,0 \%(6)$ & $40,0 \%(6)$ & $20,0 \%(3)$ \\
\hline 1.2 Possibilidades da comunidade local & $40,0 \%(6)$ & $40,0 \%(6)$ & $20,0 \%(3)$ \\
\hline 1.3 Dados sobre matrículas & $80,0 \%(12)$ & $20,0 \%(3)$ & $0,0 \%(0)$ \\
\hline 1.4 Dados sobre repetência & $66,7 \%(10)$ & $26,7 \%(4)$ & $6,7 \%(1)$ \\
\hline 1.5 Dados sobre evasão & $73,3 \%(11)$ & $20,0 \%(3)$ & $6,7 \%(1)$ \\
\hline 1.6 Caracterização da estrutura física & $53,3 \%(8)$ & $46,7 \%(7)$ & $0,0 \%(0)$ \\
\hline 1.7 Caracterização da gestão da escola & $33,3 \%(5)$ & $66,7 \%(10)$ & $0,0 \%(0)$ \\
\hline $\begin{array}{l}\text { 1.8 Definição de funções, direitos e } \\
\text { responsabilidades do pessoal da gestão }\end{array}$ & $46,7 \%(7)$ & $53,3 \%(8)$ & $0,0 \%(0)$ \\
\hline $\begin{array}{l}\text { 1.9 Definição de funções, direitos e } \\
\text { responsabilidades docentes }\end{array}$ & $46,7 \%(7)$ & $53,3 \%(8)$ & $0,0 \%(0)$ \\
\hline $\begin{array}{l}\text { 1.10 Definição de direitos e responsabilidades } \\
\text { dos/as estudantes }\end{array}$ & $53,3 \%(8)$ & $46,7 \%(7)$ & $0,0 \%(0)$ \\
\hline
\end{tabular}

FONTE: O autor (2012).

\section{Princípios e concepções de educação}

Um PPP deve contemplar os princípios que direcionam suas práticas educacionais. Adotar a EDH como uma diretriz que conduz a vida escolar significa explicitar princípios e valores que contemplem a diversidade dos estudantes e seus direitos. Neste âmbito há cinco critérios que buscam relacionar os princípios educacionais à EDH.

\section{TABELA 2 - PRINCÍPIOS E CONCEPÇÕES DE EDUCAÇÃO}

\begin{tabular}{|c|c|c|c|}
\hline $\mathrm{n}=15$ & Não menciona & Menciona & Propõe ações \\
\hline $\begin{array}{l}\text { 2.1 Define valores que pautam a educação na } \\
\text { escola }\end{array}$ & $13,3 \%(2)$ & $80,0 \%(12)$ & $6,7 \%(1)$ \\
\hline 2.2 Pauta-se por princípios de inclusão & $66,7 \%(10)$ & $26,7 \%(4)$ & $6,7 \%(1)$ \\
\hline $\begin{array}{l}2.3 \text { Refere-se à inclusão de pessoas com } \\
\text { deficiências (artigo } 24 / \text { decreto } 6.949 \text { de } 25 \text { de } \\
\text { agosto de } 2009 \text {, resolução } 002 / 01 \mathrm{CNE} / \mathrm{CEB} \text { ) }\end{array}$ & $80,0 \%(12)$ & $20,0 \%(3)$ & $0,0 \%(0)$ \\
\hline $\begin{array}{l}2.4 \text { Compreende a diversidade de formas e } \\
\text { ritmos de aprendizagem humana }\end{array}$ & $57,1 \%(8)$ & $42,9 \%(6)$ & $0,0 \%(0)$ \\
\hline $\begin{array}{l}\text { 2.5 Refere-se explicitamente aos Direitos } \\
\text { Humanos }\end{array}$ & $93,3 \%(14)$ & $0,0 \%(0)$ & $6,7 \%(1)$ \\
\hline
\end{tabular}

FONTE: O autor (2012). 


\section{Objetivos}

Qualquer projeto estabelece objetivos a serem alcançados, quando temos em mente a promoção dos direitos de todos, estes objetivos devem refletir a amplitude dos interesses e necessidades dos estudantes atendidos pela escola. Este âmbito é composto por nove critérios que buscam identificar objetivos comprometidos com a promoção de direitos.

\section{TABELA 3 - OBJETIVOS}

\begin{tabular}{l|l|l|l}
\hline $\mathrm{n}=15$ & Não menciona & Menciona & Propõe ações \\
\hline $\begin{array}{l}\text { 3.1 Há objetivos que envolvem os Direitos } \\
\text { Humanos? }\end{array}$ & $93,3 \%(14)$ & $6,7 \%(1)$ & $0,0 \%(0)$ \\
\hline $\begin{array}{l}\text { 3.2 Há objetivos que envolvem o Estatuto da } \\
\text { Criança e do Adolescente? }\end{array}$ & $64,3 \%(9)$ & $28,6 \%(4)$ & $7,1 \%(1)$ \\
\hline $\begin{array}{l}\text { 3.3 Há objetivos relacionados à melhoria do } \\
\text { espaço físico visando à acessibilidade e inclusão? }\end{array}$ & $73,3 \%(11)$ & $13,3 \%(2)$ & $13,3 \%(2)$ \\
\hline $\begin{array}{l}\text { 3.4 Há objetivos relacionados à aquisição } \\
\text { de equipamentos para a escola visando à } \\
\text { acessibilidade e inclusão? }\end{array}$ & $80,0 \%(12)$ & $6,7 \%(1)$ & $13,3 \%(2)$ \\
\hline $\begin{array}{l}3.5 \text { Há objetivos direcionados aos/às estudantes } \\
\text { com dificuldades de aprendizagem? }\end{array}$ & $20,0 \%(3)$ & $0,0 \%(0)$ & $80,0 \%(12)$ \\
\hline $\begin{array}{l}3.6 \text { Há objetivos relacionados ao enfrentamento da } \\
\text { repetência? }\end{array}$ & $53,3 \%(8)$ & $13,3 \%(2)$ & $33,3 \%(5)$ \\
\hline $\begin{array}{l}3.7 \text { Há objetivos relacionados ao enfrentamento } \\
\text { da evasão? }\end{array}$ & $53,3 \%(8)$ & $20,0 \%(3)$ & $26,7 \%(4)$ \\
\hline $\begin{array}{l}\text { 3.8 Há objetivos relacionados ao enfrentamento da } \\
\text { violência? }\end{array}$ & $46,7 \%(7)$ & $6,7 \%(1)$ & $46,7 \%(7)$ \\
\hline $\begin{array}{l}\text { 3.9 Os objetivos se articulam com a realidade da } \\
\text { escola (problemas diagnosticados e possibilidades } \\
\text { identificadas) }\end{array}$ & $46,7 \%(7)$ & $20,0 \%$ (3) & $33,3 \%(5)$ \\
\hline
\end{tabular}

FONTE: O autor (2012).

\section{Currículo}

Uma das partes de um PPPs refere-se à apresentação do currículo que estrutura as ações pedagógicas, ou seja, devem estar definidos os conteúdos e a metodologia de ensino. A EDH coloca o ser humano como central a todos os processos, assim, metodologias que atribuem ao estudante um papel ativo em processos de aprendizagem são coerentes com este tipo de educação, além de conteúdos que promovam a reflexão sobre a diversidade que caracteriza nossa sociedade. Este âmbito está composto por onze critérios relacionados aos DH e temáticas a eles pertinentes. 
TABELA 4 - CURRÍCULO

\begin{tabular}{|c|c|c|c|}
\hline $\mathrm{n}=15$ & Não menciona & Menciona & Propõe ações \\
\hline $\begin{array}{l}\text { 4.1 Busca metodologias de ensino- } \\
\text { aprendizagem focadas nos/as estudantes }\end{array}$ & $53,3 \%(8)$ & $46,7 \%(7)$ & $0,0 \%(0)$ \\
\hline $\begin{array}{l}4.2 \text { Calendário escolar inclui e celebra datas } \\
\text { relacionadas a conquistas dos DH }\end{array}$ & $86,7 \%(13)$ & $13,3 \%(2)$ & $0,0 \%(0)$ \\
\hline $\begin{array}{l}\text { 4.3 Prevê projetos relacionados à valorização } \\
\text { das diversidades }\end{array}$ & $66,7 \%(10)$ & $20,0 \%(3)$ & $13,3 \%(2)$ \\
\hline 4.4 Prevê projetos relacionados à discriminação & $73,3 \%(11)$ & $13,3 \%(2)$ & $13,3 \%(2)$ \\
\hline $\begin{array}{l}\text { 4.5 Prevê a discussão dos Direitos Humanos } \\
\text { (como disciplina, tema transversal ou temática } \\
\text { de projetos) }\end{array}$ & $93,3 \%(14)$ & $0,0 \%(0)$ & $6,7 \%(1)$ \\
\hline $\begin{array}{l}\text { 4.6 Prevê a discussão do ECA (como disciplina, } \\
\text { tema transversal ou temática de projetos) - Lei } \\
11.525 / 07\end{array}$ & $73,3 \%(11)$ & $20,0 \%(3)$ & $6,7 \%(1)$ \\
\hline $\begin{array}{l}\text { 4.7 Inclui discussões sobre gênero e diversidade } \\
\text { sexual }\end{array}$ & $80,0 \%(12)$ & $6,7 \%(1)$ & $13,3 \%(2)$ \\
\hline 4.8 Inclui a temática do meio ambiente & $53,3 \%(8)$ & $33,3 \%(5)$ & $13,3 \%(2)$ \\
\hline $\begin{array}{l}4.9 \text { Inclui a história e cultura afro-brasileira (Lei } \\
\text { Federal } 10.639 / 03 \text { ) }\end{array}$ & $86,7 \%(13)$ & $13,3 \%(2)$ & $0,0 \%(0)$ \\
\hline $\begin{array}{l}\text { 4.10 Inclui a história e cultura indígena (Lei } \\
\text { Federal } 11.645 / 08 \text { ) }\end{array}$ & $86,7 \%(13)$ & $13,3 \%(2)$ & $0,0 \%(0)$ \\
\hline $\begin{array}{l}\text { 4.11 Promove projetos e ações dos jovens } \\
\text { estudantes junto à sua comunidade visando à } \\
\text { identificação e análise dos DH em sua realidade }\end{array}$ & $93,3 \%(14)$ & $6,7 \%(1)$ & $0,0 \%(0)$ \\
\hline
\end{tabular}

FONTE: O autor (2012).

\section{Participação Democrática e ambiente escolar}

Como já mencionado para que o PPP não seja apenas uma carta de boas intenções, ele deve criar uma sinergia entre os membros da comunidade escolar, isso significa criar possibilidades para a participação democrática e atuar na consolidação de um ambiente pautado pelo diálogo, respeito e discussões coletivas de temas que envolvem toda a comunidade escolar. Ao mesmo tempo, EDH e democracia são interdependentes, pois a garantia de direitos de todos significa reconhecer, respeitar e dar voz aos diferentes grupos que integram a sociedade. O âmbito é composto por nove critérios que buscam detectar relações democráticas na escola. 
TABELA 5 - PARTICIPAÇÃO DEMOCRÁTICA E AMBIENTE ESCOLAR

\begin{tabular}{l|l|l|l}
\hline $\mathrm{n}=15$ & Não menciona & Menciona & Propõe ações \\
\hline $\begin{array}{l}\text { 5.1 Prevê a participação docente na discussão e } \\
\text { elaboração de normas/regras }\end{array}$ & $46,7 \%(7)$ & $46,7 \%(7)$ & $6,7 \%(1)$ \\
\hline $\begin{array}{l}\text { 5.2 Prevê a participação docente na escolha de } \\
\text { temas coletivos a serem trabalhados durante o } \\
\text { ano }\end{array}$ & $60,0 \%(9)$ & $40,0 \%(6)$ & $0,0 \%(0)$ \\
\hline $\begin{array}{l}\text { 5.3 Prevê a participação do pessoal de apoio } \\
\text { (merendeiras, bedel, secretários) nas discussões } \\
\text { e decisões mais gerais relacionadas ao convívio } \\
\text { escolar }\end{array}$ & $73,3 \%(11)$ & $26,7 \%(4)$ & $0,0 \%(0)$ \\
\hline $\begin{array}{l}5.4 \text { Participação da comunidade estudantil } \\
\text { em decisões que afetam sua vida na escola } \\
\text { (elaboração de regras/normas, organização de } \\
\text { festividades/campeonatos) }\end{array}$ & $20,0 \%(3)$ & $73,3 \%(11)$ & $6,7 \%(1)$ \\
\hline $\begin{array}{l}5.5 \text { Prevê vias de participação estudantil na } \\
\text { representação de seus interesses (grêmio, } \\
\text { representação discente) }\end{array}$ & $33,3 \%(5)$ & $60,0 \%(9)$ & $6,7 \%(1)$ \\
\hline $\begin{array}{l}5.6 \text { Participação dos pais/mães/responsáveis em } \\
\text { decisões da escola (em assuntos que sejam de } \\
\text { competência das famílias/responsáveis) }\end{array}$ & $6,7 \%$ (1) & $86,7 \%(13)$ & $6,7 \%(1)$ \\
\hline $\begin{array}{l}5.7 \text { Participação da comunidade local em } \\
\text { festividades promovidas pela escola }\end{array}$ & $86,7 \%(13)$ & $6,7 \%(1)$ & $6,7 \%(1)$ \\
\hline $\begin{array}{l}5.8 \text { Participação da comunidade local na } \\
\text { discussão de temas relevantes no seu cotidiano }\end{array}$ & $73,3 \%(11)$ & $20,0 \%(3)$ & $6,7 \%(1)$ \\
\hline $\begin{array}{l}5.9 \text { Há ações destinadas ao enfrentamento das } \\
\text { violências que ocorrem na escola }\end{array}$ & $60,0 \%(9)$ & $0,0 \%(0)$ & $40,0 \%(6)$ \\
\hline
\end{tabular}

FONTE: O autor (2012).

\section{Formação Docente}

A adoção da EDH como uma maneira de conduzir a vida na escola pressupõe conhecimentos acerca de seus princípios e práticas, para tanto, tornam-se necessários processos de formação continuada de docentes e funcionários que atuam na escola. Este âmbito é composto por cinco critérios que visam identificar se estas intenções formativas estão presentes no PPP. 
TABELA 6 - FORMAÇÃO DOCENTE

\begin{tabular}{l|l|l|l}
\hline $\mathrm{n}=15$ & $\begin{array}{l}\text { Não } \\
\text { menciona }\end{array}$ & Menciona & $\begin{array}{l}\text { Propõe } \\
\text { ações }\end{array}$ \\
\hline $\begin{array}{l}\text { 6.1 Prevê a formação docente em temáticas variadas } \\
\text { 6.2 Prevê a formação docente em temáticas } \\
\text { relacionadas aos DH }\end{array}$ & $33,3 \%(5)$ & $66,7 \%(10)$ & $0,0 \%(0)$ \\
\hline $\begin{array}{l}\text { 6.3 Prevê a formação docente para a implementação } \\
\text { do ECA nas escolas }\end{array}$ & $86,7 \%(13)$ & $13,3 \%(2)$ & $0,0 \%(0)$ \\
\hline $\begin{array}{l}\text { 6.4 Prevê a formação de demais funcionários da } \\
\text { escola em temáticas relativas aos DH }\end{array}$ & $93,3 \%(14)$ & $6,7 \%(1)$ & $0,0 \%(0)$ \\
\hline $\begin{array}{l}\text { 6.5 Prevê a formação dos gestores da escola em } \\
\text { temáticas relativas aos DH }\end{array}$ & $100,0 \%(15)$ & $0,0 \%(0)$ & $0,0 \%(0)$ \\
\hline
\end{tabular}

FONTE: O autor (2012).

\section{Avaliação}

A avaliação incide sobre a transmissão do conhecimento, relações entre docentes e discentes, interações, métodos, disciplina, expectativas de todos os sujeitos, valorização do indivíduo na sociedade. (SACRISTAN; GOMÉZ, 2000, p. 298). Sua função didática é fornecer elementos para pensar a prática. Para que a avaliação esteja a serviço do conhecimento ela deve ir além de suas funções classificatórias e buscar métodos e técnicas variadas que considerem a complexidade humana e a importância da autoavaliação e da heteroavaliação para o educando. Numa perspectiva pautada pelos Direitos Humanos, trata-se de colocar o estudante como centro do processo e reconhecer seus direitos no que tange ao conhecimento dos critérios que serão utilizados para avaliá-lo.

\section{TABELA 7 - AVALIAÇÃO}

\begin{tabular}{l|l|l|l}
\hline $\mathrm{n}=15$ & Não menciona & Menciona & $\begin{array}{l}\text { Propõe } \\
\text { ações }\end{array}$ \\
\hline $\begin{array}{l}\text { 7.1 Faz o diagnóstico e propõe ações específicas para } \\
\text { enfrentar problemas de evasão, repetência }\end{array}$ & $60,0 \%(9)$ & $20,0 \%(3)$ & $20,0 \%(3)$ \\
\hline $\begin{array}{l}\text { 7.2 A avaliação dos/as estudantes é utilizada para } \\
\text { identificar problemas no processo de ensino- } \\
\text { aprendizagem e replanejar as aulas }\end{array}$ & $40,0 \%(6)$ & $53,3 \%(8)$ & $6,7 \%(1)$ \\
\hline $\begin{array}{l}\text { 7.3 Atribui importância à aprendizagem socioafetiva } \\
\text { dos/as estudantes }\end{array}$ & $60,0 \%(9)$ & $33,3 \%(5)$ & $6,7 \%(1)$ \\
\hline $\begin{array}{l}\text { 7.4 São utilizados instrumentos variados na avaliação } \\
\text { dos/as estudantes }\end{array}$ & $40,0 \%(6)$ & $46,7 \%(7)$ & $13,3 \%(2)$ \\
\hline $\begin{array}{l}\text { 7.5 Prevê a discussão dos critérios e resultados da } \\
\text { avaliação com os/as estudantes }\end{array}$ & $60,0 \%(9)$ & $26,7 \%(4)$ & $13,3 \%(2)$ \\
\hline $\begin{array}{l}\text { 7.6 Prevê formas de autoavaliação ou avaliação entre } \\
\text { pares (heteroavaliação) dos estudantes }\end{array}$ & $80,0 \%(12)$ & $20,0 \%(3)$ & $0,0 \%(0)$ \\
\hline
\end{tabular}

FONTE: O autor (2012). 


\section{Considerações finais}

Um primeiro ponto a ser destacado é a dificuldade de acesso aos PPPs. Mesmo contando com o apoio da Secretaria Estadual de Educação, as escolas demonstraram-se reticentes em relação à cessão deste documento. Algumas alegam não o terem atualizado, outras afirmam que só possuem versões impressas e muitas nem responderam à solicitação. Este é um dado que pode ser interpretado de diferentes maneiras, mas algo que nos parece relevante é a forma como as instituições utilizam o documento, muitas vezes percebido como uma obrigação burocrática, sem fins práticos.

De maneira geral, os PPPs se detêm fracamente às ações capazes de concretizar seus ideais. As tabelas demonstram que as células escurecidas (que registram o maior percentual de respostas) situam-se na primeira coluna, ou seja, a que corresponde ao não menciona.

A maior ausência relaciona-se aos Direitos Humanos, em cerca de 90\% dos PPPs não há registro de datas que aludem às conquistas de direitos, tampouco sua inclusão como disciplina ou tema transversal e nem a análise da realidade local a partir dos DH. Apenas uma das escolas (6,7\%) menciona ações relacionadas ao tema. Este é um dado relevante, pois a comemoração de datas, inclusive já previstas no calendário escolar, pode ser uma via de inserção dos Direitos Humanos no currículo. Isso nos permite afirmar que os elementos mais diretamente relacionados à EDH ainda não foram incorporados pelas escolas. Fato que pode ser justificado por se tratar de uma perspectiva educacional recente.

Outro dado relevante, que nos permite refletir sobre a incorporação de novas temáticas ao currículo escolar, é a fraca presença do ensino de história afro-brasileira e indígena e a inserção do ECA (tabela 4). Este quadro demonstra que apenas leis não garantem a mudança das concepções e ações educativas. A reflexão e a discussão sobre tais temas apresentam-se como uma necessidade da comunidade escolar, pois não se trata apenas de cumprir legislações, pelo contrário, para modificar-se algo é necessário que as pessoas tenham consciência sobre aquilo que se pretende e acreditem que a mudança é necessária e possível. Evidentemente que isto não se faz de maneira impositiva, para mudar é preciso desejar transformar, compreender, estar informado, conhecer, perceber como estes temas estão presentes na realidade escolar, enxergar o que está presente e muitas vezes não é percebido por falta de conhecimento sobre o assunto.

Os dados relacionados ao currículo (tabela 4) demonstram que as escolas incorporam em seus discursos a preocupação com metodologias que valorizam a participação e o protagonismo discentes, mas não incorporam a este discurso 
a relação entre conteúdos e realidade dos estudantes, ou seja, os temas não são problematizados a partir daquilo que os alunos vivenciam. Outro ponto importante é que não preveem ações, projetos ou estratégias para que essas metodologias se exercitem na prática.

No que concerne à participação democrática e ambiente escolar (tabela 5), percebe-se que a participação dos funcionários e da comunidade local é mencionada de maneira incipiente e apenas $6,7 \%$ dos PPPs propõem ações para a sua efetivação. Outro dado interessante é que a participação dos pais $(86,7 \%)$ é mais mencionada do que a participação dos estudantes (73,11\%), embora em ambos os casos haja apenas $6,7 \%$ de menção a ações para que isto se concretize.

A análise de PPPs nos permite identificar os aspectos mais valorizados pelas escolas. No âmbito objetivos (tabela 3), os maiores percentuais de ações propostas relacionam-se às dificuldades de aprendizagem (80\%) e ao enfrentamento da violência (47\%). As escolas têm como um dos seus grandes desafios concretizar os direitos de aprendizagem de seus alunos/as e esta preocupação traduz-se na forma de proposição de ações pedagógicas. $\mathrm{O}$ mesmo pode ser afirmado em relação ao enfrentamento à violência, preocupação refletida nas ações dos PPPs.

Outro dado importante relaciona-se à formação de docentes e funcionários da escola, este âmbito (tabela 6) não apresenta a proposição de nenhuma ação. Como viabilizar a formação dos profissionais de uma escola se esta não é uma meta delineada e planejada? Formar docentes/funcionários pressupõe levantar as temáticas que são importantes para o grupo, estabelecer prioridades formativas, buscar cursos de formação, organizar organogramas de trabalho, enfim, há uma série de decisões necessárias que precisam ser discutidas pela comunidade escolar e serem registradas no Projeto Político-Pedagógico. Convém destacar que a formação docente inicial e continuada em EDH é um dos pontos das Diretrizes Nacionais para a Educação em Direitos Humanos. (BRASIL, 2012). Esse dado corrobora com outros dados apresentados que apontam a não inserção dos $\mathrm{DH} \mathrm{e}$ do ECA no currículo. Cursos de formação continuada podem ser uma via para a inserção de tais conteúdos no currículo escolar e também para transformar as relações escolares. Além do mais, as formações precisam ir além de conteúdos conceituais de forma a propor a reflexão sobre valores e atitudes, uma vez que a EDH não trata apenas de conhecimento ou informações a serem transmitidos aos estudantes, trata-se antes de tudo de construir uma cultura que instaure um modo de vida na escola no qual se vivenciem os direitos no dia a dia, de forma viva.

Em relação à avaliação (tabela 7), percebe-se que 53\% dos PPPs concebem a avaliação como parte do processo de ensino-aprendizagem e entendem que esta tem uma função importante no planejamento do professor. Em $20 \%$ dos documentos encontra-se a intenção de utilizar a avaliação diagnóstica no 
enfrentamento da evasão e repetência. Estes fenômenos são importantes e preocupantes quando temos por princípio que a educação e a aprendizagem são direitos de todos.

Outro ponto que merece destaque é a discussão dos resultados da avaliação com os estudantes (presente em 40\% dos PPPs) e a utilização de instrumentos variados (60\% dos PPPs). A avaliação tem efeitos que se estendem para além da sala de aula e marcam a vida de uma pessoa, além de refletirem na autoimagem que os estudantes constroem. Portanto, é um tema delicado que envolve relações de poder entre professor-aluno e têm efeitos sociais e psicológicos sobre quem é avaliado.

A análise de PPPs configura-se como um campo profícuo para a identificação das concepções, valores e ações das escolas e pode auxiliar no diagnóstico dos pontos mais frágeis das instituições e que necessitam de medidas pontuais.

Especificamente em relação aos Direitos Humanos podemos analisar sua presença nos PPPs por meio de três perspectivas diferentes. A primeira relaciona-se ao seu conteúdo intencionalmente proposto como tema ou matéria de discussão e aprendizagem, neste caso, percebemos uma fraca presença ou quase inexistência do mesmo. A segunda perspectiva relaciona-se às temáticas a eles relacionadas como diversidade sexual, valorização cultural, meio ambiente e o ECA, que aparecem de forma discreta, pouco expressiva. A terceira refere-se à concretização dos $\mathrm{DH}$ no ambiente escolar, no sentido de construir um ambiente promotor de direitos. Neste caso, percebemos ações e discursos que destacam a importância de metodologias de ensino e técnicas avaliativas que favorecem a participação ativa dos estudantes e priorizam a aprendizagem. O mesmo pode ser afirmado em relação à preocupação em enfrentar dificuldades de aprendizagem dos estudantes. Reconhecer que todos podem aprender e têm este direito é essencial para que o direito à educação se concretize. $\mathrm{O}$ enfrentamento à violência pode representar a tentativa do respeito mútuo e ao mesmo tempo a construção de relações pautadas pelo diálogo, compreensão, generosidade e tolerância.

A análise destes documentos demonstra que as escolas trazem em seus PPPs elementos que concretizam princípios e valores da EDH, no entanto, isto não está diretamente relacionado com a promoção deste tipo de educação. Em nosso entendimento, falta às escolas o conhecimento e a intencionalidade para incorporar a EDH de maneira sistemática e crítica ao currículo. Este é um processo lento que confronta concepções, valores e práticas docentes, demandando formações, discussões e estudos sobre o tema. 


\section{REFERÊNCIAS}

BRASIL. Estatuto da Criança e do Adolescente. São Paulo: Cortez, 1990.

BRASIL. Comitê Nacional de Educação em Direitos Humanos. Plano Nacional de Educação em Direitos Humanos, 2006. Brasília: Secretaria Especial dos Direitos Humanos, Ministério da Educação, Ministério da Justiça, UNESCO, 2006.

BRASIL. Secretaria de Direitos Humanos da Presidência da República. Programa Nacional de Direitos Humanos (PNDH-3). 2. ed. rev. e atual. Brasília: SDH/PR, 2010.

BRASIL. Ministério de Educação. Diretrizes Curriculares Nacionais para a Educação em Direitos Humanos. Resolução CNE/CP 1/2012. Diário Oficial da União, Brasília, 31 de maio de 2012, Seção 1.

GADOTTI, Moacir. Pressupostos do projeto pedagógico. In: MEC. Conferência nacional de educação para todos. Anais... Brasília, 1994.

ONU. Declaração Universal dos Direitos Humanos. Genebra, 1945.

ONU, UNESCO, OHCHR. Plan de acción: Programa Mundial para la educación en derechos humanos. Primeira etapa. Nueva York y Genebra, 2006.

SACRISTÁN, José Gimeno; GOMÉZ, A. Pérez. Compreender e transformar o ensino. 4. ed. Porto Alegre: Artmed, 2000.

VEIGA. (Org.). Projeto político-pedagógico da escola: uma construção possível. 23. ed. Campinas: Papirus, 2001.

VEIGA. Inovações e projeto político-pedagógico: uma relação regulatória ou emancipatória? Cad. Cedes, Campinas, v. 23, n. 61, p. 267-281, dez. 2003.

Texto recebido em 30 de outubro de 2014 .

Texto aprovado em 19 de março de 2015. 